\title{
SUMBERDAYA PENDORONG KEUNGGULAN BERSAING PERUSAHAAN
}

\author{
Cut Nina Rostina, SE, MM \\ cutnina@gmail.com \\ Universitas Teuku Umar
}

\begin{abstract}
Understanding sources of sustained competitive advantage has become a major area of research in strategic management. Building on the assumptions that strategic resources are heterogeneously distributed across firms and that these differences are stable over time, this article examines the link between firm resources and sustained competitive advantage. Four empirical indicator of the potential of firm resources to generate sustained competitive advantage-value, rareness, imitability, and substitutability-are discussed.
\end{abstract}

Keywords: resources based view, kompetensi, sumberdaya

\section{Pendahuluan}

Penggunaan sumberdaya memiliki banyak keunggulan potensial bagi perusahaan seperti pencapaian efisiensi yang lebih besar dan selanjutnya biaya yang lebih rendah, peningkatan kualitas dan kemungkinan pangsa pasar serta profitabilitas yang lebih besar (Collis, 1994). Pendekatan analitis yang disebut Resource-Based View (RBV) menekankan peningkatan keunggulan bersaing yang berasal dari sumberdaya strategis organisasi (Dierickx and Coll, 1989; Barney, 1991; Peteraf, 1993; dan Teece et al., 1997). Keunggulan bersaing (competitive advantage) memungkinkan perusahaan memperoleh kinerja unggul pada jangka waktu tertentu (Pitts and Lei, 2003:7). Inti dari RBV adalah bahwa perusahaanperusahaan berbeda secara fundamental karena memiliki seperangkat sumberdaya (Grant, 2002:139; Fleisher and Bensoussan, 2003:187). Pencapaian keunggulan bersaing yang paling efektif adalah dengan menggunakan kompetensi perusahaan (Wernerfelt, 1984; Barney, 1986a; Rumelt, 1991; Evans, 1991; Peteraf, 1993; Amit and Schoemaker, 1993).

Pendekatan RBV menyatakan bahwa perusahaan dapat mencapai keunggulan bersaing yang berkesinambungan dan memperoleh keuntungan superior dengan memiliki atau mengendalikan aset-aset strategis baik yang berwujud maupun yang tidak berwujud. Menurut pendekatan RBV, perusahaan merupakan sekumpulan sumberdaya strategis dan produktif yang unik, langka, kompleks, saling melengkapi dan sulit untuk ditiru para pesaing yang dapat dimanfaatkan sebagai elemen untuk mempertahankan strategi bersaingnya.

Perkembangan teori dan empiris sekarang ini membuktikan bahwa perusahaan dengan kompetensisuperior akan menghasilkan informasi yang lebih baik mengenai kebutuhan dan keinginan pelanggannya dan juga lebih baik dalam 


\section{Jurnal Bisnis dan Kajian Strategi Manajemen}

Volume 1 Nomor 2, 2017

ISSN : 2614-2147

http://jurnal.utu.ac.id/jbkan

membangun dan memasarkan barang atau jasa melalui aktivitas yang terkordinasi dengan baik. Lebih lanjut, kompetensi superior juga memberi perusahaan kemampuan untuk menghasilkan dan bertindak berdasarkan pengetahuan mengenai aksi dan reaksi pesaing, yang akan membantunya membangun keunggulan bersaing (Naver and Slater, 1990; Touminen et al., 1997).

\section{Pembahasan \\ Definisi Kompetisi}

Teece et al. (1997) melihat sumberdaya sebagai "aset-aset khusus perusahaan yang sulit, yang jika mungkin tidak dapat ditiru, dimana kompetensi dihasilkan dari integrasi asset-aset khusus perusahaan." Kompetensi merupakan kemampuan dan pengetahuan perusahaan yang menjadi dasar pemecahan masalah sehari-hari (Henderson and Cockburn, 1994). Definisi lain menyatakan bahwa kompetensi adalah kemampuan perusahaan untuk mengekploitasi sumberdaya yang berbeda, dengan menggunakan berbagai proses organisasi untuk mencapai hasil yang diinginkan (Grant, 1991; Amit and Schoemaker, 1993). Helfat and Peteraf (2002)mendefinisikan sumberdaya sebagai aset atau input untuk melakukan kegiatan produksi baik berwujud maupun tidak berwujud yang dimiliki dan dikendalikan oleh perusahaan atau memiliki akses ke barang semipermanen lain. Sedangkan Wheelen and Hunger (2002:81) mendefinisikan sumberdaya sebagai aset, kompetensi, proses, keahlian atau pengetahuan yang dikendalikan oleh perusahaan.

Capron and Hulland (1999) mendefinisikan sumberdaya sebagai sejumlah pengetahuan, aset fisik, manusia, dan faktor-faktor berwujud dan tidak berwujud lainnya yang dimiliki atau dikendalikan perusahaan, yang memungkinkan perusahaan untuk menghasilkan secara efektif dan efisien penawaran pasar yang bernilai untuk beberapa segmen pasar. Sumberdaya, menurut Barney (1991) meliputi semua aset seperti keahlian, proses organisasi, atribut, informasi dan pengetahuan yang dikuasai oleh perusahaan dan yang menyebabkan perusahaan dapat menyusun dan mengimplementasikan strategi yang meningkatkan efisiensi dan efektivitas.

Kompetensi didasarkan pada informasi, proses-proses berwujud dan tidak berwujud, dan mengembangkannya sepanjang waktu melalui interaksi yang kompleks antara dan diantara sumberdaya (Amit and Schoemaker, 1993). Kekuatan suatu perusahaan yang tidak dapat dengan mudah ditandingi atau ditiru oleh pesaing disebut kompetensi (David, 2002:142). Kompetensi juga dinyatakan sebagai kemampuan mengorganisir pekerjaan dan menyampaikan nilai; kompetensi dapat meliputi komunikasi, keterlibatan dan komitmen yang besar untuk bekerja sepanjang batas-batas organisasi (Prahalad and Hamel, 1990; Kogut and Zander, 1992). Kompetensi juga dapat dirasakan sebagai aset-aset perantara yang diturunkan perusahaan untuk meningkatkan produktifitas sumberdayanya, seperti fleksibilitas strategi dan perlindungan terhadap produk dan jasa-jasa akhir perusahaan (Amit and Schoemaker, 1993). 


\section{Jurnal Bisnis dan Kajian Strategi Manajemen}

Volume 1 Nomor 2, 2017

ISSN : 2614-2147

http://jurnal.utu.ac.id/jbkan

Bogner and Thomas (1994) mendefinisikan kompetensi inti sebagai keahlian khusus yang dimiliki perusahaan dan pengetahuan yang diarahkan untuk mencapai tingkat kepuasan konsumen yang lebih tinggi dibandingkan pesaingnya. Selanjutnya kompetensi inti adalah keahlian yang memungkinkan perusahaan mencapai dasar-dasar customer benefits (Hamel and Heene, 1994:87) melalui pembentukan, peningkatan, pembaharuan dan penggunaan sumberdaya yang membawa pada keunggulan bersaing yang berkelanjutan.

Untuk mempertahankan keunggulan bersaing, kompetensi inti haruslah menambah nilai, sulit digantikan, sulit bagi pesaing untuk meniru, dan dapat dipindahkan sepanjang perusahaan (Barney, 1991; Grant, 1991, 1996). Lebih lanjut, setidaknya empat mekanisme dikaitkan dengan kompetensi, yakni timecompression diseconomies, efisiensi aset massa,keterkaitan antar aset, dan causal ambiguity (Dierickx and Cool, 1989) yang membantu melindungi aset darikeusangan dan keunggulan bersaing yang berkelanjutan yang dihasilkan dari kompetensi inti.

Kompetensi haruslah mengintegrasikan sejumlah keahlian atau teknologi, menjadi kekuatan bersaing yang unik, dan memberikan kontribusi pada nilai serta memberikan kemampuan untuk masuk ke pasar yang baru (Prahalad and Hamel, 1990; Hamel and Heene, 1994). Bogner and Thomas (1994) yang mendefinisikan kompetensi inti sebagai keahlian khusus yang dimiliki perusahaan dan pengetahuan yang diarahkan untuk mencapai tingkat kepuasan konsumen yang lebih tinggi dibandingkan pesaingnya.

\section{Dimensi Kompetensi}

Oliver (1997) memberikan perhatian pada sumberdaya strategis dan berargumen bahwa sumberdaya yang menghasilkan kompetensi haruslah langka, unik, khusus, tak berwujud, sulit ditiru diganti dan sulit ditiru. Meyer and Utterback (1993) menekankan peran penting kompetensi teknologi, penelitian dan pengembangan, kompetensi produksi dan manufaktur, serta kompetensi pemasaran.

Selanjutnya Hamel and Heene (1994) membagi kompetensi menjadi kompetensi akses-pasar, kompetensi yang berkaitan dengan integrasi, dan kompetensi dikaitkan dengan fungsionalitas. Hall (1994) percaya bahwa kemampuan fungsional, budaya, posisi, dan pengaturan sebagai pembentuk dan penentu keunggulan perusahaan secara keseluruhan.

Barney (1991) menyajikan struktur yang lebih konkret dan komprehensif untuk mengidentifikasi pentingnya kompetensi untuk memperoleh keunggulan bersaing yang berkesinambungan. Barney (1991) mengutarakan empat indikator sehingga kompetensi yang dimiliki perusahaan dapat menjadi sumber keunggulan bersaing yang berkesinambungan, yakni: bernilai (valuable), merupakan kompetensi langka diantara perusahaan-perusahaan yang ada dan pesaing potensial (rare), tidak mudah ditiru (inimitability), dan tidak mudah digantikan (non-substitutability).

1. Bernilai (valuable) 


\section{Jurnal Bisnis dan Kajian Strategi Manajemen}

Volume 1 Nomor 2, 2017

ISSN : 2614-2147

http://jurnal.utu.ac.id/jbkan

Kompetensi bernilai (valuable competencies) adalah kompetensi yang menciptakan nilai bagi suatu perusahaan dengan mengeksploitasi peluang-peluang atau menetralisir ancaman-ancaman dalam lingkungan eksternal perusahaan. Kompetensi dapat menjadi sumber keunggulan bersaing yang berkesinambungan hanya ketika kompetensi tersebut bernilai (valuable). Kompetensi dikatakan bernilai ketika kompetensi tersebut menyebabkan perusahaan mampu menyusun dan mengiplementasikan strategi-strategi yang dapat meningkatkan nilai bagi pelanggan khususnya.

\section{Langka (rareness)}

Kompetensi langka adalah kompetensi yang dimiliki oleh sedikit, jika ada, pesaing saat ini atau potensial. Kompetensi perusahaan yang bernilai namun dimiliki oleh sebagian besar pesaing yang ada atau pesaing potensial tidak dapat menjadi sumber keunggulan bersaing yang berkesinambungan. Sebuah perusahaan dikatakan menikmati keunggulan bersaing ketika perusahaan tersebut dapat mengimplementasikan strategi penciptaan nilai yang tidak dapat dilakukan oleh sebagian besar perusahaan lainnya. Dengan kata lain, keunggulan bersaing dihasilkan hanya ketika perusahaan mengembangkan dan mengeksploitasi kompetensi yang berbeda dari pesaingnya. Jika kompetensi yang bernilai tadi dimiliki oleh sebagian besar perusahaan, dan tiap-tiap perusahaan memiliki kemampuan untuk menggunakannya dengan cara dan teknik yang sama, dan selanjutnya mengimplementasikan strategi yang hampir sama maka dapat dikatakan tidak ada satupun perusahaan yang memiliki keunggulan bersaing.

\section{Sulit Ditiru (Inimitability)}

Kompetensi yang bernilai dan langka tersebut hanya dapat menjadi sumber keunggulan bersaing yang berkesinambungan jika perusahaan lain yang tidak memilikinya, tidak dapat memperoleh kompetensi tersebut. Dalam istilah yang dibangun oleh Lippman and Rumelt (1982) dan Barney (1986a), kompetensi ini disebut sangat sulit ditiru (imperfectly imitable). Kompetensi dapat dikatakan sulit ditiru karena satu atau kombinasi dari tiga alasan berikut:

a. Kemampuan perusahaan untuk memperoleh kompetensi tergantung pada kondisi historis yang unik. Ketika perusahaan berevolusi, mereka mengambil keahlian, kemampuan, dan sumberdaya yang unik bagi mereka, mencerminkan jalan setapak yang dilalui dalam sejarah (Barney, 1995). Cara lain untuk mengatakan ini adalah bahwa kadang-kadangperusahaan mampu mengembangkan kompetensi karena berada pada tempat yang tepat dan saat yang tepat (Barney, 1999).

b. Hubungan antara kompetensi yang dimiliki oleh perusahaan dengan keunggulan bersaing yang berkesinambungan bersifat ambigu (causally ambiguous). Para pesaing tidak mampu memahami dengan jelas bagaimana suatu perusahaan menggunakan kompetensi intinya sebagai dasar 


\section{Jurnal Bisnis dan Kajian Strategi Manajemen}

Volume 1 Nomor 2, 2017

ISSN : 2614-2147

http://jurnal.utu.ac.id/jbkan

\section{Sulit Digantikan (Insubstitutability)}

dari keunggulan bersaingnya. Akibatnya para pesaing tidak pasti tentang kompetensi-kompetensu yang harus mereka kembangkan untuk meniru manfaat dari strategi penciptaan nilai perusahaan yang disainginya itu

c. kompetensi yang menghasilkan keunggulan perusahaan tersebut bersifat kompleksitas sosial (socially complex). Kompleksitas sosial berarti bahwa setidaknya beberapa, dan sering kali banyak, kompetensi perusahaan adalah produk dari fenomena sosial yang kompleks. Contoh kompetensi yang kompleks secara sosial meliputi relasi antar pribadi, kepercayaan, dan persahabatan di antara manajer dan antar manajer dengan pegawai serta reputasi perusahaan dengan pemasok dan pelanggan.

Kompetensi yang sulit digantikan adalah kompetensi yang tidak memiliki ekuivalen strategis. Dua sumberdaya perusahaan yang bernilai (atau dua kumpulan sumberdaya perusahaan) ekuivalen secara strategis ketika tiap sumberdaya itu dapat dieksploitasi secara terpisah untuk mengimplementasikan strategi-strategi yang sama. Secara umum, nilai strategis dari kompetensi meningkatkan kesulitan untuk menggantikannya. Semakin tidak terlihat suatu kompetensi, semakin sulit bagi perusahaan untuk mencari penggantinya dan semakin besar tantangan bagi para pesaing untuk meniru strategi penciptaan nilai perusahaan.

Keunggulan bersaing sebuah perusahaan harus didasarkan pada sumberdaya khusus yang menjadi penghalang (barriers) aktivitas peniruan dan ancaman pengganti (imitation and substitution) produk atau jasa perusahaan. Meningkatnya tekanan persaingan dapat menurunkan keunggulan bersaing perusahaan. Hal ini mengindikasikan bahwa bagi sebuah perusahaan, agar tetap bertahan hidup (survive) di tengah tekanan persaingan yang semakin tajam, perusahaan harus mengambil tindakan yang dapat mempertahankan dan memperkuat kompetensinya yang unik (Reed and DeFillipi, 1990). Sumberdaya dan kompetensi perusahaan dapat ditempatkan dalam sebuah kontinum untuk melihat bahwa sumberdaya dan kampetensi tersebut tahan lama dan tidak dapat ditiru. Kontinum keberlanjutan (continuum of sustainability) sumberdaya tersebut dijelaskan pada Gambar 1.

Pada titik sebelah kiri, terdapat siklus sumberdaya yang lambat yang berarti sumberdaya tersebut tahan lama. Hal ini disebabkan sumberdaya dilindungi oleh paten, geografi, nama merek yang kuat atau ilmu pengetahuan yang dimiliki. Sumberdaya dan kapabilitas ini merupakan kompetensi khusus, karena memberikan keunggulanbersaing berkelanjutan. Titik di sebelah kanan menggambarkan siklus sumberdaya yang cepat, yang dihadapkan pada tekanan peniruan yang sangat tinggi. Sumberdaya dan kapabilitas pada kondisi ini didasarkan pada konsep atau teknologi yang dapat dengan mudah ditiru. Untuk 
perusahaan yang memiliki siklus sumberdaya yang cepat seperti ini, jalan utama agar perusahaan dapat bersaing dengan sukses adalah melalui ditingkatkannya kecepatan jalur antara penelitian perusahaan dengan pasar dimana produk akan dijual.

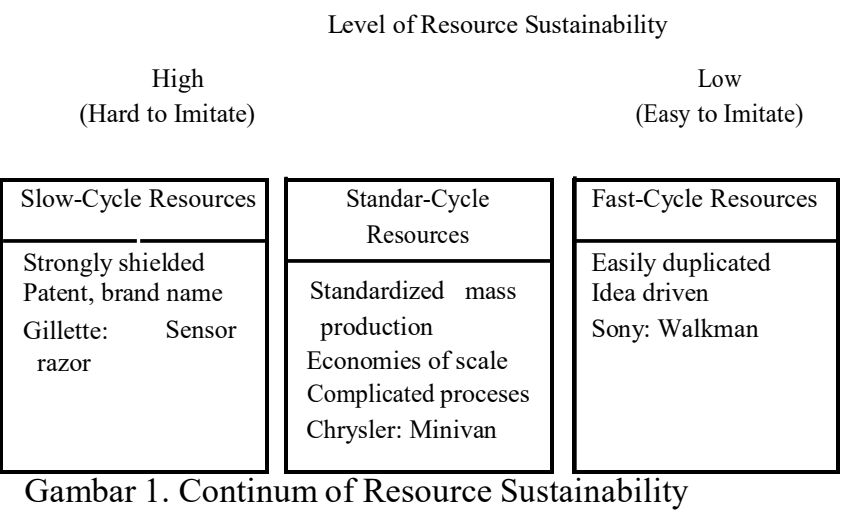

Sumber: Williams, 1992. How Sustainability is Your Competitive Advantage? California Management

Review, Spring, p.33

Prahalad and Hamel (1989) menemukan bahwa perusahaan yang sukses adalah perusahaan yang berfokus pada peningkatan kompetensi, yang digunakan dengan cara-cara baru dan inovatif untuk mencapai tujuan. Perhatian utama perusahaan adalah menggunakan sumberdayanya dalam cara-cara yang menantang dan kreatif untuk membangun kompetensi inti.

Kompetensi memiliki pengaruh yang kuat terhadap kinerja perusahaan (Absah, 2007). Perusahaan yang memiliki tim manajemen dengan keahlian optimal dan metode bersaing yang didasarkan pada kompetensi inti akan mampu mencapai kinerja yang lebih tinggi dibandingkan perusahaan lain yang tidak dapat melakukannya.

Dengan kompetensi superior akan memungkinkan perusahaan memperoleh informasi apa yang dibutuhkan dan diinginkan oleh pelanggannya. Dengan demikian, perusahaan yang memiliki karyawan dengan kompetensi yang tinggi, akan lebih mampu menyediakan produk dan layanan yang sesuai dengan kebutuhan dan keinginan pelanggan. Oleh karena itu, perusahaan dengan kompetensi superior dapat memperoleh keunggulan bersaing yang berkesinambungan dan selanjutnya dapat meningkatkan kinerjanya. Agar dapat mempertahankan keunggulan bersaing tersebut, kompetensi yang dimiliki perusahaan haruslah mampumenambah nilai, langka, sulit ditiru, dan sulit digantikan.

Menurut Godfrey and Hill (1995), kompetensi yang tidak mudah ditiru merupakan inti (poros) dari teori resource-based, dan sentral pemahaman mengenai keunggulan bersaing yang berkelanjutan (Dierickx and Cool, 1989; Spender and Grant, 1996). Selanjutnya Pace et al. (2005) menemukan bahwa kompetensi yang sulit ditiru memiliki hubungan yang positif dengan kinerja.

Kompetensi mungkin dilindungi dari peniruan dengan berbagai cara. Kompetensi yang berasal dari faktor sejarah seperti lokasi yang strategis, 


\section{Jurnal Bisnis dan Kajian Strategi Manajemen}

Volume 1 Nomor 2, 2017

ISSN : 2614-2147

http://jurnal.utu.ac.id/jbkan

kepemilikan hak cipta, akan melindungi sumberdaya bernilai tersebut dari tindakan peniruan oleh pesaing. Sumberdaya yang bersifat socially complex, seperti reputasi yang baik dan kepercayaan merupakan sumberdaya yang membutuhkan waktu dan biaya yang tinggi untuk ditiru. Terakhir, causal ambiguity merupakan ambiguitas mengenai hubungan antara kompetensi perusahaan dengan keunggulan bersaing (Reed and DeFillipi, 1990; Barney, 1991) akan melindungi kompetensi dari usaha peniruan (Lippman and Rumelt, 1982; Dierickx and Cool, 1989; Barney,1991). Causal ambiguity akan melindungi kompetensi dari usaha peniruan karena pesaing tidak mengerti hubungan antara kompetensi ini dengan keunggulan bersaing.

Pengetahuan yang dimiliki karyawan perusahaan menjadi salah satu kompetensi yang sulit ditiru. Pengetahuan akan menjadi kompetensi yang sulit untuk ditiru karena membutuhkan waktu yang lama dan biaya yang mahal untuk ditiru. Selain itu seseorang dengan keahlian khusus yang dimiliki perusahaan akan menjadi menjadi keunggulan strategis dan merupakan basis bagi kinerja superior. Seperti juga yang ditemukan oleh Hatch and Dyer (2004) bahwa pesaing tidak dapat dengan cepat dan murah meniru atau mengganti nilai dari sumberdaya manusia khusus yang dimiliki perusahaan. Beberapa penelitian lain juga menemukan bahwa keunggulan bersaing akan berlanjut bila didasar pada sumberdaya manusia yang tak berwujud dan bersifat sociallycomplex (Arthur,

1994; Huselid, 1995; Kock and McGrath, 1996).

Causal ambiguity dijelaskan dalam literaturdengan dua cara berbeda. Pertama, linkage ambiguity adalah ambiguitas diantara pengambil keputusan mengenai hubungan antara kompetensi dengan keunggulan bersaing (Lippman and Rumelt, 1982; Barney, 1991). Kedua, characterictic ambiguity yang difokuskan pada karakter dari kompetensi, yang sekaligus merupakan sumber keunggulan dan ambiguitas. Characterictic ambiguity adalah ambiguitas yang melekat pada sumberdaya itu sendiri.

Ketertutupan (tacitness) merupakan salah satu karakteristik causally ambiguity (Reed and DeFillippi, 1990; Barney, 1995; Godfrey and Hill, 1995; Hart, 1995; Szulanski, 1996; Inkpen and Dinur, 1998; Simonin, 1999). Tacitness merefleksikan bahwa sebuah kompetensi adalah "intuitif, non-verbal dan tidak terucapkan" (Hedlund and Nonaka, 1993:118). Tacit knowledge lebih ambigu dibandingkan articulates atau explisit knowledge (Winter, 1987;Reed and DeFillippi, 1990; Kogut and Zander, 1992). Pengetahuan eksplisit dijabarkan sebagai "formal, sistematik dan tujuan yang ditunjukkan dalam kata atau angka" (Baker et al., 1997). Pengetahuan eksplisit dapat diturunkan dari sejumlah sumber yang meliputi data, proses bisnis, kebijakan dan prosedur, serta sumber eksternal seperti informasi pasar (Baker et al., 1997). Sedangkan pengetahuan tacit berupapengetahuan, pengalaman, keahlian, model mental, intuisi dan kepercayaan (Baker et al., 1997), yang sangat dinamis dan khusus (Martensson, 2000; Tsoukas and Vladimirou, 2001). Kompetensi juga dikarakteristikkan sebagai causally ambiguous ketika kompetensi tersebut berada dalam budaya dan nilai-nilai 


\section{Jurnal Bisnis dan Kajian Strategi Manajemen}

Volume 1 Nomor 2, 2017

ISSN : 2614-2147

http://jurnal.utu.ac.id/jbkan

organisasi (Masakowski, 1997) karena kompetensi yang berada dalam budaya mungkin lebih pasti dan kurang mobile dibandingkan dengan pengetahuan yang berada pada individu atau sekelompok kecil. Itami and Roehl (1987) menyatakan bahwa elemen kunci strategi adalah mengelola aset-aset tak bewujud (seperti keahlian, reputasi, dll.).

Penelitian yang dilakukan oleh Bharadwaj etal. (1993) menemukan bahwa keunggulan bersaingsangat penting dalam mencapai kinerja superior pada perusahaan jasa. Dimana keunggulan bersaing dapat diperoleh dengan memiliki seperangkat keahlian dan kompetensi yang unik sehingga sulit ditiru oleh para pesaing. Dukungan juga diberikan oleh Mehra (1996) yang menemukan bahwa terdapat hubungan yang kuat antara sumberdaya yang dimiliki perusahaan dengan kinerja yang lebih tinggi. Selanjutnya hasil penelitian Pace et al. (2005) menemukan bahwa berdasarkan pendekatan Resource-Based View (RBV), penyebab utama perbedaan kinerja diantara perusahaan adalah karena perbedaan sumbersumberdaya khusus dan akumulasi kompetensi yang dimiliki perusahaan. Penelitian ini menguji hubungan antara kinerja persaingan dengan sumberdaya strategis yang dimiliki perusahaan. Melalui metodologi riset yang dibangun oleh Rudolphe Durand, diperoleh hasil yang memuaskan mengenai hubungan antara tingkat pengaruh kompetensi dengan kinerja perusahaan. Hasil penelitian ini menunjukkan bahwa kompetensi yang semakin sulit untuk ditiru (imitability) dan semakin sulit untuk dipindahkan (immobility)menyebabkan profitabilitas, margin dan kinerja pasar yang lebih tinggi. Ditemukan bahwa kompetensi yang sulit ditiru memiliki hubungan yang positif hanya dengan kinerja pasar (market performance). Sedangkan kompetensi yang sulit untuk dipindahkan (immobility) ditemukan memiliki hubungan positif dengan profitabilitas dan berhubungan negatif dengan margin. Hasil studi ini juga konsisten dengan Pace etal. (2005). yang menemukan adanya hubungan antaraprofitabilitas dengan sumberdaya dan bagaimana mengelolanya. O'Regan and Ghobadian (2004) juga menemukan bahwa kompetensi perusahaan memiliki pengaruh positif terhadap strategi dan pencapaian kinerja secara keseluruhan.

Namun demikian studi yang dilakukan Fernandes et al. (2005) yang berjudul resources thatdrive performance: an empirical investigation memberikan hasil yang berbeda. Fernandes et al. melakukan penelitian pada perusahaan air minum Brazil mengenai sumberdaya yang menghasilkan kinerja perusahaan berdasarkan praktek sumberdaya manusia, kompetensi karyawan dan sumberdaya berwujud lainnya serta melakukan evaluasi kinerja berdasarkan model Balanced- Scorecarad. Fernandes et al. menemukan bahwa secara umum sumberdayamemiliki pengaruh terhadap kinerja, namun bila bila diteliti lebih jauh maka ditemukan bahwa kompetensi karyawan justru tidak berpengaruh terhadap kinerja; faktor-faktor lingkungan yang dikaitkan dengan permintaan merupakan faktor yang paling kuat mempengaruhi kinerja; serta kepuasan karyawan berpengaruh pada semua perspektif BSC. 


\section{KESIMPULAN}

Pendekatan resource-based menekankan pentingnya sumberdaya internal untuk mencapai keunggulan bersaing yang berkelanjutan. Perspektif ini menyatakan bahwa kinerja perusahaan adalah fungsi dari seberapa baik manajer membangun organisasinya dalam menangani sumberdaya yang bernilai, langka, sulit ditiru dan sulit digantikan (Barney, 1991). Perusahaan dengan kompetensi yang bernilai dan langka akan menghasilkan keunggulan bersaing yang lebih besar dibandingkan pesaingnya, yang selanjutnya menghasilkan kinerja keuangan superior. Keunggulan bersaing dan kinerja yang dihasilkan perusahaan merupakan konsekuensi dari sumberdaya khusus dan kompetensi yang dimiliki. Dengan demikian dapat dikatakan bahwa perusahaan harus memiliki kemampuan untuk mengkordinasikan sumberdaya strategis dengan baik, sebab merupakan kunci dalam membangun kompetensi dan pada akhirnya pencapaian kinerja yang tinggi. DAFTAR PUSTAKA

Absah, Yeni, 2007. Pengaruh Pembelajaran Organisasi, Kompetensi,dan Tingkat Diversifikasi terhadap Kinerja Perguruan Tinggi Swasta di Sumatera Utara, Disertasi, Surabaya, Universitas Airlangga.

Amit, R. and P.J.H. Schoemaker, 1993. StrategicAssets and Organizational Rent, StrategicManagement Journal, Vol.14, pp.33-46.

Arthur,J.B., 1994. Effect of Human Resource Systems on Manufacturing Performance andTurnover, Academy of Management Journal,Vol.37, No.3, pp.670-687.

Baker, M., M. Barker, J. Thorne and M. Dutnell, 1997. Leveraging Human Capital,TheJournal of Knowledge Management, Vol.1,No.1, pp.63-74. Barney, J.B., 1986a. Strategic Factor Markets:Expectations, Luck and Business Strategy, Management Science, Vol.32, pp.1231-1241.1988. Return to Bidding Firms in Mergers and Acquisitions: reconsidering theRelatedness Hypothesis, StrategicManagement Journal, Vol.9, No.1, pp.71-78.

1991. Firm Resources and Sustained Competitive Advantage, Journal ofManagement, Vol.17, No.1, pp.99-120.

, 1995. Looking Inside for Competitive Advantage, Academy of ManagementExecutive, Vol.9, No.3, pp.59-60.

, 1999. How a Firms Capabilities Effect Boundary Decisions, Sloan ManagementReview, Vol.40, N0.3, pp.137-145.

2002. Gaining and Sustaining CompetitiveAdvantage, $2^{\text {nd }}$ edition, Upper Saddle River,New York: Prentice-Hall.

Bharadwaj, S.G., P.R. Varadarajan and J. Fahi, 1993 Suatinable Competitive Advantage in Service Industries: A Conseptual Model and Research Propositions, Journal of Marketing, Vol.57, October, pp.84-99.

Bogner, W.C. and H. Thomas, 1994. Core Competences and Competitive Advantage: A Model and Illustrative Evidence from Pharmaceutical Industry, in Hamel, G. and W. 
Heene (Eds.), Competences -basedCompetition, New York: John Wiley \& Sons. Capron L. and J. Hulland, 1999. Redeployment of Brand, Sales Forces and General Marketing Management Expertise Following Horizontal Acquisitions: A Resource-based View, Journal of Marketing, Vol.63, April, pp.41-54.

Collis D.J., 1994. How Valuable are Organizational Capabilities? Strategic Management Journal, Vol.15, pp.143-152.

David, F.R., 2002. Manajemen Strategis: Konsep, Edisi Bahasa Indonesia. Diterjemahkan oleh Alexander Sindoro. Jakarta: Prenhallindo.

Dierickx, I. and K. Cool, 1989. Asset Stock Accumulation and Sustainability of Competitive Advantage, ManagementScience, Vol.35, pp.88-108.

Evans, J.S. 1991. Strategic Flexibility for High Technology Manoeuvers: a Conceptual Framework, Journal of Managerial Studies, Vol.28, No.1, pp.69-89.

Fernandes, B.H., J.F. Mills and M.T. Fleury, 2005. Resources that Drive Performance: An Empirical Investigation, International Journal of Productivity and Performance Management, Vol.54, No.5/6, pp.340-354.

Fleisher, C.S and B.E. Bensoussan, 2003. Strategicand Competitive Analysis: Methods and Techniques for Analysis Business Competition, New York: Prentice-Hall,Englewood Cliffs.

Godfrey, P.C. and C.W.L. Hill, 1995. The Problem of Un-observables in Strategic Management Research, Strategic Management Journal, Vol.16, No.9, pp.519-533.

Grant, R.M., 1991. The Resource-Based Theory of Competitive Advantage: Implications for Strategy Formulation, CaliforniaManagement Review, spring, pp.114-135.,1996. Prospering in Dynamically-competitive Advantage, Organizational Capabilities as Knowledge Integration, OrganizationalScience, Vol. 7, July-August, pp.375-387.

Hall, R., 1994. A Framework for Identifying the Intangible Sources of Sustainable Competitive Advantages, in Hamel G. and A. Heene (Eds), Competencebased Competition, Chichester:John Willey \& Sons.

Hamel, G. and A. Heene, 1994. Competence- basedCompetition, Chichester: John Willey \& Sons.

Hart, S.L., 1995. A Natural Resource-based View of the Firm, Academy of Management Review, Vol.20, pp.986-1014.

Hatch, N.W. and J.H. Dyer, 2004. Human Capital and Learning as a Source of Sustainable Competitive Advantage, StrategicManagement Journal, Vol.25, pp.1155-1178.

Hedlund, S. and L. Nonaka, 1993. A Model of Knowledge Management and in the West and Japan. In Implementing Strategic Process:Change, Learning, and Cooperation, LorangeP., Chakravharty P., Roos J., and Van de Ven (eds), Oxford: Basil-Blackwell, pp.117-144. 